\title{
Komunitas Ikan di Perairan Danau Wilayah Sulawesi Utara dan Gorontalo
}

\author{
Fish Communities in North Sulawesi and Gorontalo Lakes
}

\section{Haryono}

Bidang Zoologi, Puslit Biologi-LIPI, Gd. Widyasatwaloka, Jl. Raya Bogor Km. 46 Cibinong 16911; Telp.(021)8765056/64,Fax(021)8765068,Email: ikharyono@yahoo.com

\begin{abstract}
The study of lake fishes community in North Sulawesi and Gorontalo provinces was done during July and August 2001. The lakes of study were Tondano (St.1), Moat (St.2), Tondok (St.3) and Limboto (St.4) under observation methods to determine the fishes diversity, abundance, local distribution, status and economy values. There were 17 different species from 12 families screened during this study, the Cyprinidae was the dominant one and consist of three species. Overall the variation of fishes consist of eight introducable species and nine native species. The most abundance species was Ophieleotris aporos and the most wide distributed was Cyprinus carpio, mostly species have economic values. Comparing to three other lakes, the Limboto has the most various species of fishes.
\end{abstract}

Key words: lake fishes, North Sulawesi and Gorontalo, Cyprinus carpio, Ophieleotris aporos

Diterima: 16 Juli 2003, disetujui: 11 September 2003

\section{Pendahuluan}

Sulawesi adalah pulau terbesar keempat di Kepulauan Indonesia, dan merupakan pulau terbesar di Wallacea. Sebagai zona peralihan antara fauna Oriental (Asiatik) dengan Australia maka di kawasan Wallacea banyak dijumpai jenis hewan yang unik dan endemik (Kinnaird, 1997; Whitten et al., 1987). Salah satu kelompok hewan yang menarik untuk diteliti pada kawasan tersebut adalah ikan.

Jenis ikan di Indonesia diperkirakan mencapai 8500 spesies (Adisoemarto dan Rifai, 1992), dan di dunia sampai saat ini sudah diketahui ada 24618 jenis ikan (Nelson, 1994). Di Sulawesi, keberadaan ikan air tawar tercatat 62 jenis dan 52 di antaranya merupakan jenis endemik (Kottelat et al., 1993). Namun demikian Whitten et al. (1987) mengatakan bahwa Sulawesi tidak mempunyai jenis ikan yang benar benar merupakan ikan air tawar murni atau divisi primer, tetapi hanya beberapa jenis yang termasuk divisi sekunder, dan sebagian besar merupakan anggota divisi perifer.

Jenis ikan endemik di Sulawesi umumnya berkaitan dengan keberadaan danau. Di Sulawesi terdapat 13 buah danau dengan luas keseluruhan mencapai $5 \mathrm{~km}^{2}$, tersebar di lima provinsi dengan kedalaman dan letak ketinggian tempat yang sangat bervariasi (Whitten et al., 1987).

Di Sulawesi Utara yang saat ini terbagi menjadi dua wilayah provinsi (Sulawesi Utara dan Gorontalo) terdapat tiga danau besar, yaitu danau (D) . Tondano, D. Limboto dan D. Moat. Di dekat D. Moat terdapat D. Tondok yang ukurannya jauh lebih kecil dari ketiga danau lainnya.

Sampai saat ini data mengenai ikan danau di wilayah provinsi Sulawesi Utara dan Gorontalo belum banyak dilaporkan. Di sisi lain, gangguan yang mengancam kelestarian ikan danau di kawasan tersebut semakin serius; antara lain pendangkalan danau, penggunaan alat tangkap ikan yang tidak ramah lingkungan, 
dan introduksi jenis ikan lain yang dinilai hanya sudut ekonomi saja tanpa mempedulikan ekosistemnya.

Sebagai upaya untuk melengkapi data ikan danau pada kedua provinsi tersebut, maka dilakukan penelitian dengan tujuan untuk mengetahui keanekaragaman jenis (biodiversitas), kelimpahan, distribusi, status dan potensi ikan-ikan tersebut.

\section{Metode Penelitian}

Penelitian dilakukan di danau yang terdapat di wilayah provinsi Sulawesi Utara dan Gorontalo meliputi D. Tondano di Kabupaten Minahasa, D. Moat dan D. Tondok di Kabupaten Bolaang Mongondow (Provinsi Sulawesi Utara), serta D. Limboto di
Kabupaten Gorontalo (Provinsi Gorontalo) Penelitian dilakukan bulan Juli sampai Agustu 2001 menggunakan metode observasi.

Setiap danau dianggap sebagai sat stasiun, yaitu St.1 (D. Tondano), St.2 (D Moat), St.3 (D. Tondok) dan St.4 (D. Limboto (Gambar 1). Pada setiap stasiun dibuat sub stasiun sebagai tempat pengambilan sampe ikan dan pengamatan aspek terkait agar lebil representatif. Pengambilan sampel ikan pad setiap sub-stasiun menggunakan jala yan ditebar 15 kali, jaring insang yang dipasan selama 2 jam dengan ulangan 3 kali, da elektrofishing dengan sumberdaya 2 buah acc (baterai kering) masing-masing 12 volt, 1 amper selama 1 jam.

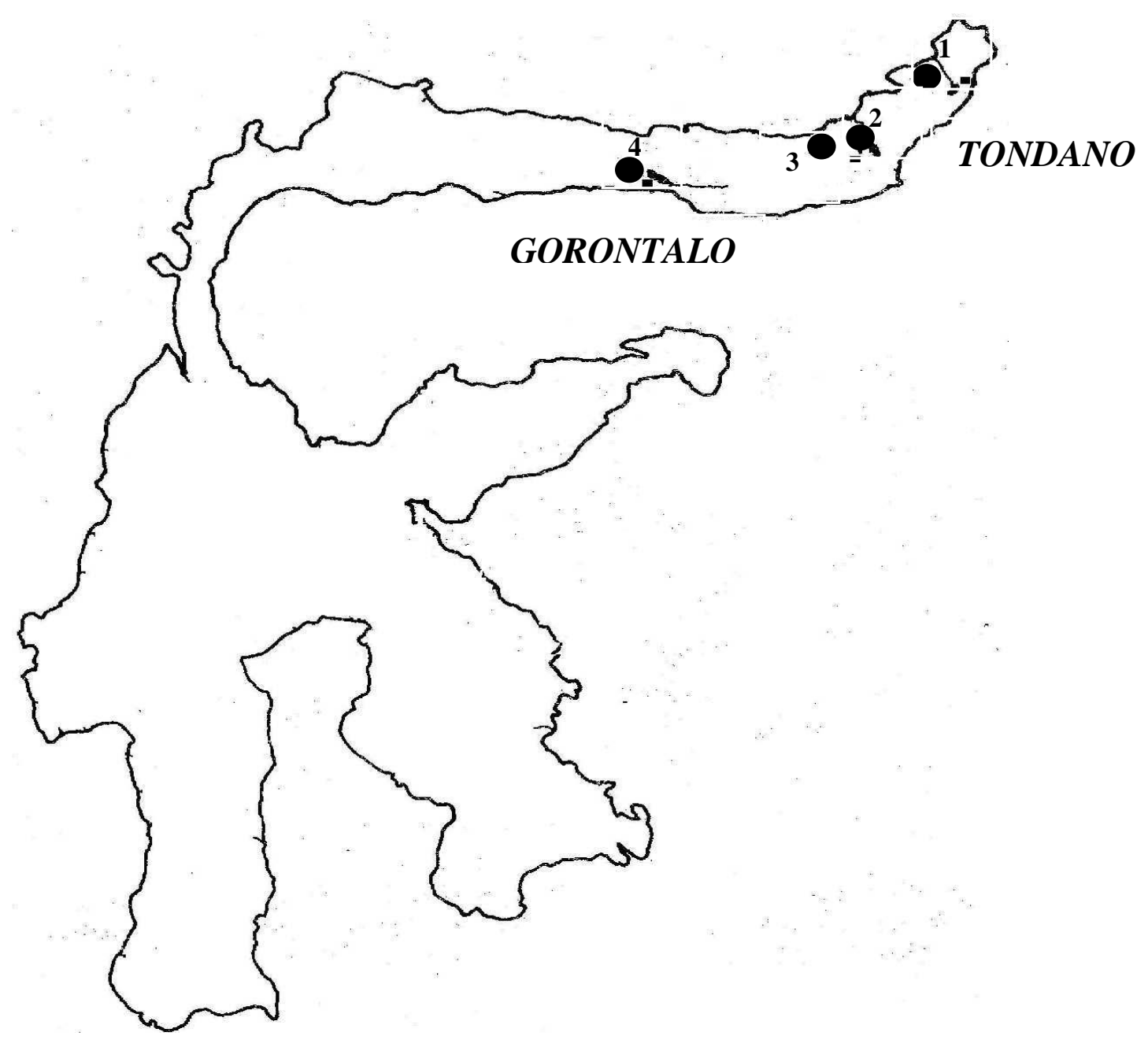

Gambar 1. Peta lokasi penelitian (1: D. Tondano, 2: D. Moat, 3: D. Tondok dan 4: D. Limboto) 
Ikan yang tertangkap dikelompokkan berdasarkan jenisnya, kemudian dihitung jumlah individu masing-masing jenis. Selanjutnya semua ikan diawetkan dalam larutan formalin $10 \%$ dalam botol yang telah dilengkapi dengan label yang berisi keterangan singkat yang diperlukan. Di laboratorium sampel ikan dicuci dalam air mengalir dan dibersihkan dari larutan formalin dengan cara direndam dalam air selama beberapa jam. Selanjutnya disimpan dalam larutan alkohol 10\% untuk dijadikan koleksi ilmiah di Museum Zoologi Bogor yang sekarang bernama Bidang Zoologi, Puslit Biologi-LIPI di Cibinong.

Untuk mengetahui nama ilmiahnya dilakukan identifikasi di Laboratorium Ikan, Bidang Zoologi, Puslit Biologi-LIPI dengan mengacu Allen (1991), Inger and Chin (1990), Weber and Beaufort (1913, 1916, 1953), Eschmeyer (1998), Roberts (1989, 1993), Kottelat et al. (1993) dan Axelrods et al. (1995).

Data kuantitatif dianalisa untuk mengetahui indeks keanekaragaman jenis menurut Shannon-Wiener (Southwod, 1971; Odum, 1971); indeks kemerataan (Pielou, 1966), indeks kekayaan jenis menurut Margalef (Southwod, 1971; Odum, 1971), dan indeks kesamaan jenis menurut Sorensen (Southwod, 1971; Odum, 1971). Kelimpahan dihitung dengan rumus ni/St (ni: jumlah individu jenis ke-i , dan St: jumlah stasiun yang dihuni jenis tersebut). Distribusi lokal dihitung dengan rumus $\boldsymbol{n S t . i / N . S t} x \quad 100 \%$ (n.St.i: jumlah stasiun yang di huni jenis ke-i, dan N.St: jumlah stasiun keseluruhan).

\section{Hasil dan Pembahasan}

\section{Biodiversitas}

Ditemukan 17 jenis ikan yang tergolong ke dalam 15 marga dan 12 suku, Cyprinidae merupakan suku yang paling dominan dengan tiga jenis (Lampiran 1). Jumlah jenis ikan yang ditemukan pada penelitian ini sedikit lebih banyak daripada yang dilaporkan oleh Soeroto dan Tungka (1996) pada lokasi yang sama yaitu 15 jenis ikan. Sistematika jenis ikan yang ditemukan dari keempat danau yang diteliti sebagai berikut:

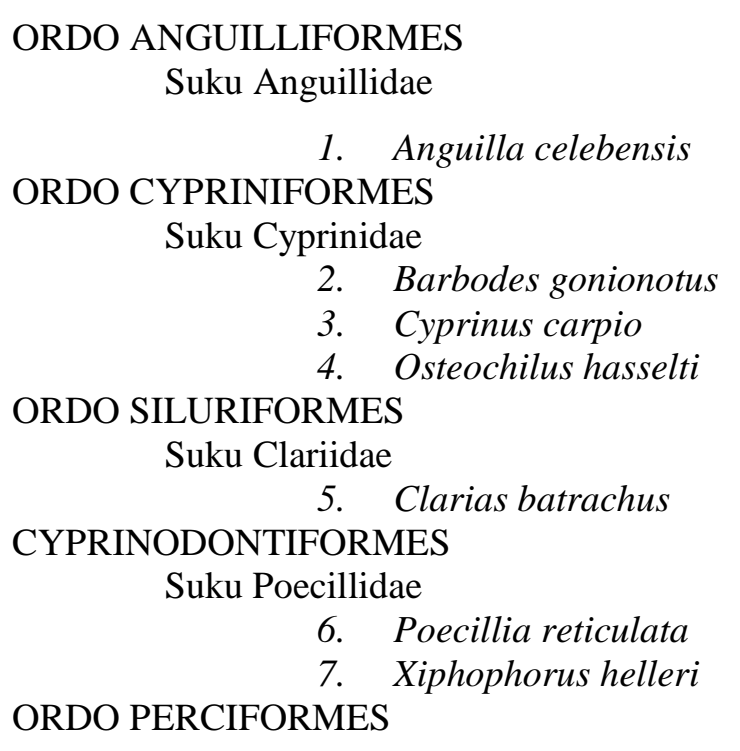

Jenis-jenis ikan di atas jika ditinjau berdasarkan kemampuan toleransi terhadap salinitas bisa dikelompokkan ke dalam tiga group/divisi, yaitu divisi Primer (lima suku: Cyprinidae, Clariidae, Anabantidae, Belontiidae dan Channidae), Sekunder (dua suku: Poecillidae dan Cichlidae) dan Peripheral (5 suku: Anguillidae, Lutjanidae, Mugillidae, Eleotrididae dan Gobiidae) (Gambar 2). Dijelaskan oleh Myers $(1938,1951)$ dan Darlington (1957), bahwa suku yang termasuk ke dalam divisi primer bersifat sedikit atau 
sama sekali tidak toleran terhadap air asin atau laut; divisi sekunder agak toleran terhadap air asin, dan divisi peripheral mempunyai toleransi tinggi terhadap air asin sehingga bisa berpindah-pindah antara laut dan perairan tawar.

Pada Gambar 2 dapat dilihat bahwa dari 17 jenis ikan yang ditemukan pada keempat danau yang diteliti, delapan jenis di antarany termasuk ke dalam divisi primer. Namu demikian kedelapan jenis tersebut buka merupakan penghuni asli Sulawesi Sebagaimana dikatakan oleh Kottelat et a (1993) dan Whitten et al. (1987), bahwa d Sulawesi tidak ada satupun jenis ikan asli yan termasuk ke dalam divisi primer.

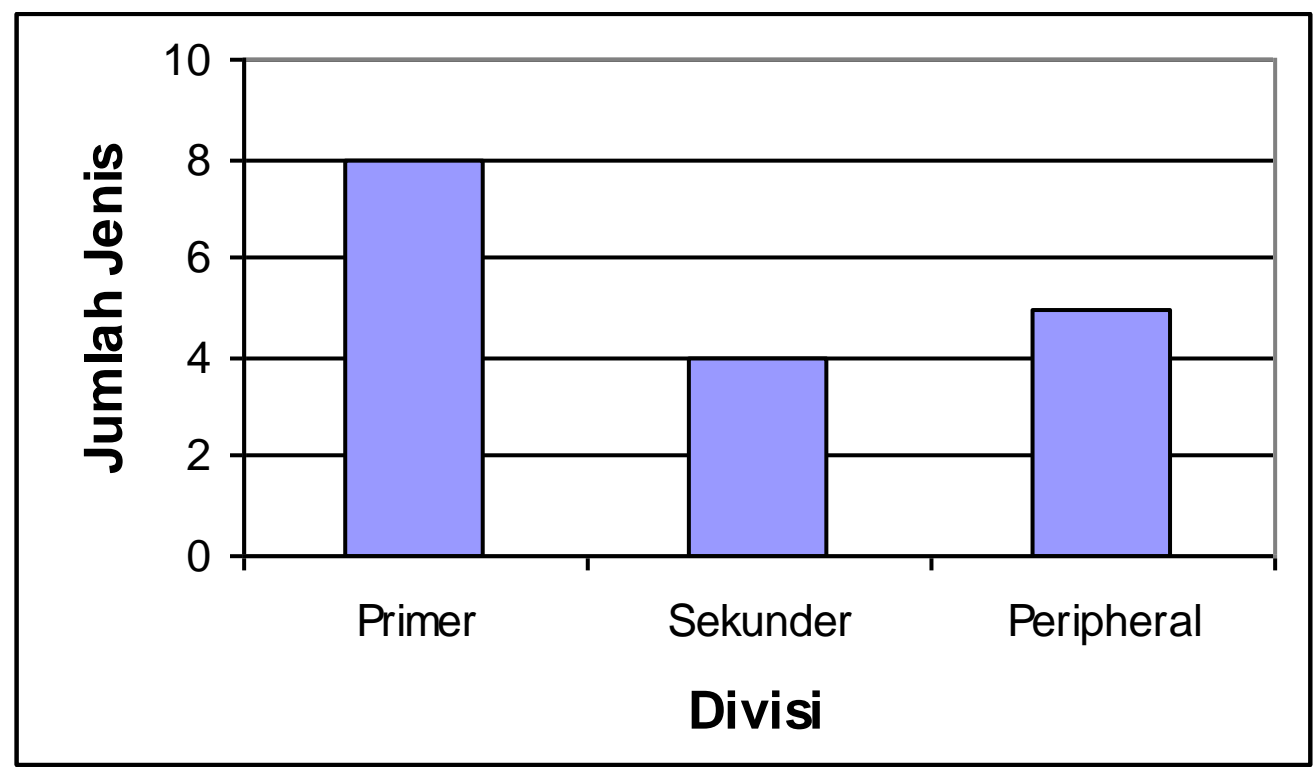

Gambar 2. Jumlah jenis ikan yang ditemukan dari setiap divisi

\section{Status dan Potensi}

Berdasarkan statusnya, ikan yang ditemukan terdiri dari sembilan jenis penghuni asli Sulawesi, delapan jenis ikan pendatang atau introduksi; sedangkan jenis ikan endemik tidak ditemukan. Berkaitan dengan jenis ikan endemik, sampai saat ini di perairan wilayah Sulawesi Utara dan Gorontalo baru ditemukan satu jenis yaitu Tondanoichthys kottelati anggota suku Hemirhampihidae. Jenis ini ditemukan di danau Tondano (Collete, 1995). Begitu pula dengan Soeroto dan Tungka (1996), juga tidak menemukan ikan danau yang endemik di wilayah kedua provinsi tersebut.

Secara keseluruhan Sulawesi memang kaya dengan jenis ikan endemik. Persentase antara jenis endemik terhadap total jenis ikan mencapai $76 \%$ (52 endemik dari 62 keseluruhan jenis). Persentase tersebut paling tinggi dibandingkan pulau-pulau lain di Indonesia (Kottelat et al., 1993). Hasil penelitian sampai saat ini melaporkan bahwa penemuan jenis baru dan endemik sebagian besar terdapat di danau di wilayah Sulawes Tengah dan Selatan. Namun tidak menutu] kemungkinan di danau-danau yang diteliti jug terdapat jenis endemik. Tidak terungkapny jenis endemik pada penelitian ini bisa pul dikarenakan kurang intensifnya penelitia karena keterbatasan waktu. Sebaliknya sanga disesalkan jika yang terjadi seperti yan dikhawatirkan oleh Whitten et al. (1987) bahwa beberapa jenis ikan endemik yan menghuni danau-danau di Sulawesi bisa puna akibat kalah bersaing dengan jenis ika introduksi yang banyak dibudidaya ole masyarakat.

Berdasarkan potensi (nilai ekonomi nya, ikan yang ditemukan hampir keseluruha berpotensi sebagai ikan konsumsi. Di antar jenis-jenis tersebut yang paling banya dijumpai di pasar lokal adalah ikan nila $(C$ niloticus), mas (Cyprinus carpio), dan gabu (Channa striata). Ikan nila dan ikan ma banyak dibudidaya dalam jaring apun terutama di danau Tondano dan Limboto. 
Kebanyakan ikan konsumsi penting di Sulawesi adalah hasil introduksi baik secara sengaja maupun tidak sengaja (Whitten et al.,
1987). Proses introduksi tersebut sudah mulai sejak lama, untuk lebih jelasnya bisa dilihat pada Tabel 1 .

Tabel 1. Jenis ikan dan perkiraan tahun introduksinya

\begin{tabular}{llccc}
\hline \multirow{2}{*}{ Suku } & \multicolumn{1}{c}{ Jenis } & \multicolumn{3}{c}{ Lokasi } \\
\cline { 2 - 5 } & & Moat & Limboto & Tondano \\
\hline CYRPINIDAE & Barbodes gonionotus & + & - & 1954 \\
& Osteochilus hasselti & + & + & 1941 \\
Cyprinus carpio & + & + & 1895 \\
BELONIIDAE & Clarias batrachus & + & - & 1975 \\
OSPHRONEMIDAE & Trichogaster trichopterus & - & - & 1938 \\
HELOSTOMTIDAE & Trichogaster pectoralis & - & 1947 & 1938 \\
CICHLIDAE & Helostoma temmincki & + & - & 1914 \\
& Oreochromis mossambica & - & - & - \\
\multicolumn{1}{c}{ Sumbers $:$ Whitten } & O. nilotica & - & 1942 & 1951 \\
& & & - & 1871 \\
\hline
\end{tabular}

Sumber: Whitten et al. (1987)

Selain ikan konsumsi ditemukan pula jenis yang potensial sebagai ikan hias, diantaranya Xiphophorus helleri yang aslinya dari Amerika Tengah dengan warna dan bentuk tubuh yang sangat indah/menarik; Trichogaster trichopterus dengan warna dasar perak kemerahan disertai tiga bercak hitam yang menawan di sisi tengah tubuh; dan Glossogobius aureus dengan warna dan perilaku yang menarik. Selain itu terdapat pula ikan lele bule (Clarias batrachus), warna tubuhnya merah keputihan/bule yang bisa dimanfaatkan baik sebagai ikan hias maupun ikan konsumsi. Akan tetapi menurut informasi dari penduduk setempat bahwa ikan tersebut masih jarang dikonsumsi.

\section{Kelimpahan dan distribusi}

Jenis ikan yang melimpah adalah Ophieleotris aporos sebanyak 68 individu. /stasiun (ind/st), diikuti Xiphophorus helleri (50,33 ind./st), Trichogaster trichopterus (40,75 ind./st), Oreochromis niloticus $(44,67$ ind./st) dan Osteochilus hasselti (33 ind./st) (Lampiran 1).

Ikan payangka (Ophieleotris aporos) paling melimpah di D. Tondano, menyukai bagian perairan yang dangkal baik di danau maupun sungai, dan merupakan ikan konsumsi bernilai rendah. Jenis ini mudah berkembang biak dan tidak banyak diburu sehingga sangat mendukung kelimpahannya. Jenis Xiphophorus helleri paling melimpah di D. Moat, habitatnya di bagian tepi danau yang dangkal. Cukup melimpahnya jenis ini diduga juga karena mudah dan cepat berkembang biak. Jenis $T$. trichopterus paling melimpah di D. Tondano, habitatnya tepian danau yang banyak tanaman air.

Ketiga jenis ikan yang melimpah tersebut sampai saat ini belum banyak dimanfaatkan oleh penduduk. Hal ini sangatlah mendukung tingginya kelimpahan selain akibat kemampuan adaptasi dan berkembang biak yang tinggi. Hasil pengamatan secara keseluruhan menunjukkan bahwa sebagian besar jenis ikan yang ditemukan paling melimpah di D. Tondano. Kecenderungan ini kemungkinan berkaitan pula dengan jumlah nelayan yang masih jauh lebih sedikit dibandingkan D. Limboto.

Jenis yang terdistribusi paling luas adalah Cyrpinus carpio dan T. trichopterus masing-masing $11.11 \%$, diikuti Xiphoporus helleri dan Oreochromis niloticus masingmasing 8\%. (Lampiran 1; Gambar 3).

Hasil pengamatan tampak bahwa pada umumnya jenis-jenis ikan yang terdistribusi secara luas adalah ikan yang bernilai ekonomi tinggi, baik sebagai ikan konsumsi maupun 
ikan hias. Jenis-jenis tersebut merupakan jenis introduksi terkecuali ikan payangka (Ophieleotris aporos). Dengan demikian faktor campur tangan manusia sangat berperan dalam distribusi jenis ikan di perairan danau yang diteliti.

Hal menarik yang terkait dengan distribusi ini adalah ditemukannya beberapa jenis ikan yang termasuk divisi peripheral di D. Limboto. Jenis yang dimaksud adalah Anguilla celebensis, Lutjanus argentimaculatus Vallamugil sp. dan Glossogobius sp. Jenis-jeni di atas hanya ditemukan di D. Limboto karen danau ini terletak pada ketinggian yang palin rendah dibandingkan ketiga danau lainnya serta dekat dan berhubungan dengan laut. $\mathrm{Ha}$ ini sependapat dengan Whitten et al. (1987 yang mengatakan bahwa D. Limboto bertip genangan atau depresi yang relatif dangkal da dahulunya dilalui oleh sebuah sungai.

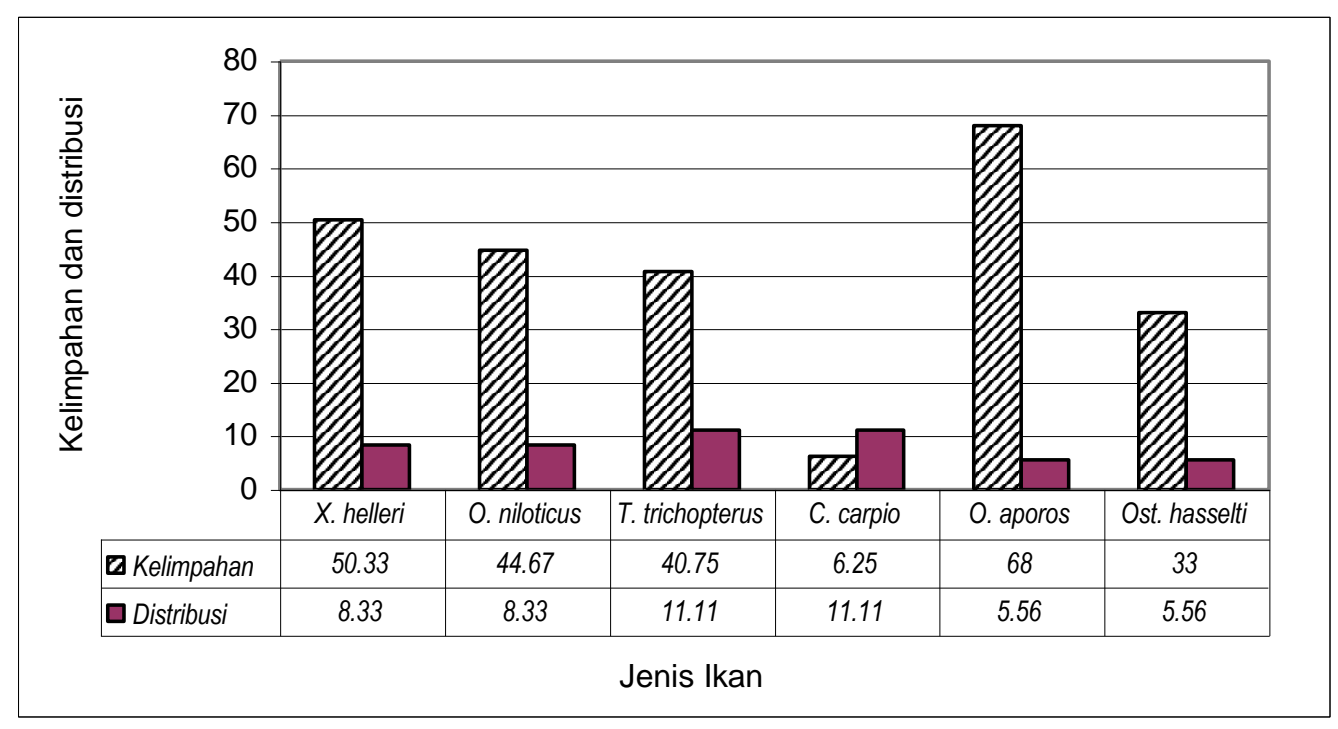

Gambar 3. Kelimpahan (ind./st) dan distribusi (\% keterdapatan) beberapa jenis ikan predominan

Pada Gambar 3 dapat dilihat bahwa sebagian besar ikan yang melimpah dan terdistribusi cukup luas merupakan jenis introduksi, kecuali ikan payangka (Ophieleotris aporos) yang merupakan ikan asli Sulawesi. Hal ini menunjukkan bahwa jenis ikan introduksi cenderung menguasai habitat pada danau-danau yang terdapat di wilayah Sulawesi Utara dan Gorontalo. Dengan demikian secara tidak langsung keberadaan ikan asli Sulawesi akan semakin terancam. Jika hal ini terus berlangsung maka sangat disayangkan karena data ikan air tawar pada danau-danau di wilayah kedua propinsi tersebut masih belum lengkap. Oleh karena itu dalam pengembangan sektor perikanan khususnya yang terkait dengan introduksi jenis ikan tertentu, jangan hanya melihat aspek ekonominya saja tetapi aspek ekologis juga sangat penting untuk dipertimbangkan. Bila terjadi kesalahan kebijakan, misalnya introduksi jenis ikan yan cepat besar tetapi bersifat predator, antaranya ikan piranha (Serrasalmus spp. maka akan berakibat fatal berupa kepunaha jenis ikan asli. Saat ini kerabat piranha, yait bawal air tawar (Colossoma macrophomum sudah tersebar luas di perairan air tawa Indonesia. Menurut informasi pendudu setempat, ikan bawal air tawar juga pernal ditemukan di danau Tondano. Padahal jeni ikan ini seperti kerabatnya, yaitu bersifat raku terhadap makanan dan berkecenderunga kanibalisme.

\section{Perbandingan antar danau}

Hasil analisis terhadap beberap nilai/indeks terkait nampak bahwa D. Limbot paling tinggi tingkat keanekaragaman maupun 
kekayaan jenisnya $(\mathrm{H}: 1.949$ dan $\mathrm{R}$ : 2.606), diikuti dengan D. Tondano (H: 1.414 dan R: 2.389); sedangkan yang paling rendah adalah D. Tondok (H: 0.430 dan R: 0.651).
Tingkat kesamaan jenis yang tertinggi dijumpai antara D. Moat dan D. Tondano sebesar 67\%. Hasil selengkapnya disajikan pada Tabel 2.

Tabel 2. Hasil analisis indeks terkait

\begin{tabular}{lcccc}
\hline \multirow{2}{*}{ Indeks } & \multicolumn{4}{c}{ Danau } \\
\cline { 2 - 5 } & Tondano & Limboto & Moat & Tondok \\
\hline Keanekaragaman jenis (H) & 2.89 & 2.606 & 1.086 & 0.651 \\
Kekayaan jenis (R) & 6.569 & 2.760 & 0.517 & 0.310 \\
Kemerataan (E) & 1.414 & 1.949 & 0.929 & 0.430 \\
Kesamaan jenis (Is) dua danau: & & & & \\
Tondano & - & 64 & 67 & 50 \\
Limboto & & - & 42 & 35 \\
Moat & & - & - & 60 \\
\hline
\end{tabular}

Tingkat keanekaragaman dan kekayaan jenis ikan pada masing-masing danau yang diteliti nampaknya terkait dengan letak ketinggian tempat dan luas danau itu sendiri. Kecenderungan ini bisa dilihat pada D. Limboto yang terletak pada ketinggian $15 \mathrm{~m}$ dpl. dan luas danaunya paling besar, maka nilai indeks keanekaragaman maupun kekayaan jenisnya juga paling tinggi. Sebaliknya pada D. Tondok yang terletak pada ketinggian sekitar $800 \mathrm{~m}$ dpl. dan luasannya paling kecil maka nilai kedua indeks tersebut juga paling rendah. Sejalan dengan fakta di atas, Bishop (Kottelat et al., 1993) mengatakan bahwa semakin besar ukuran perairan pada umumnya akan semakin besar jumlah dan keanekaragaman jenisnya. Pola seperti ini terscermin pula pada kesamaan jenis dari masing-masing danau, yaitu D. Tondano dan D. Moat yang terletak pada ketinggian tempat dan luasannya tidak jauh berbeda maka jenis ikannya juga paling mirip (Is: 67\%), dan sebaliknya D. Limboto dan D. Tondok yang letak ketinggian tempat dan luasnya berbeda jauh maka tingkat kesamaan jenisnya paling rendah (Is: $35 \%$ ).

\section{Kesimpulan}

1. Tercatat ada 17 jenis yang tergolong ke dalam 15 marga dan 12 suku ikan yang dijumpai dalam penelitian. Cyprinidae merupakan suku ikan yang paling dominan dengan tiga jenis.

2. Terdapat delapan jenis ikan pendatang dan sembilan jenis ikan asli Sulawesi, lima suku anggota divisi primer, dua suku divisi sekunder dan lima suku divisi peripheral.

3. Ophieleotris aporos merupakan jenis ikan yang paling melimpah dan Cyprinus carpio merupakan jenis ikan yang terdistribusi paling luas.

4. Sebagian besar jenis ikan yang ditemukan berpotensi sebagai ikan konsumsi.

5. Danau Limboto merupakan danau yang memiliki tingkat keanekaragaman maupun kekayaan jenis paling tinggi.

\section{Ucapan terima kasih}

Penelitian ini dibiayai oleh Nagao Natural Environmental Foundation (NEF), terima kasih kepada Abdul Munim yang telah membantu pelaksanaan penelitian di lapangan, begitu pula kepada semua pihak yang telah membantu baik dalam penelitian maupun penulisan makalah ini. 


\section{Daftar Pustaka}

Adisoemarto, S. dan M. Rifai. 1992. Keanekaragaman Hayati di Indonesia. Kantor Meneg KLH dan Konphalindo, Jakarta.

Allen, G.R. 1991. Field Guide to the Freshwater Fishes of New Guinea. Christensen Research Institute, Madang, Papua New Guinea.

Axelrods, N; W.E. Burgess; and C.W. Emmens. 1995. Mini Atlas of Freshwater Fishes, Mini editions. T.F.H. Publications, Inc., Boston.

Collette, B.B. 1995. Tondanoichthys kottelatti, a New Genus and Species of Freshwater Halfbeak (Teleostei; Hemirhamphidae from Sulawesi. Ichthyol. Explor. Freshwaters 6(2): 171-174.

Darlington, P.J. 1957. Zoogeography: the Geographical Distribution of Animals. John Wiley \& Sons, Inc., New York.

Eschmeyer, W.N. 1998. Catalog of Fishes Vol. IIII. California Academy of Sciences, San Fransisco.

Inger, R.F. and P.K. Chin. 1990. The freshwater fishes of North Borneo. Fieldiana: Zoology, vol. 45. Reprinted by: Sabah Zoologycal Society. Sabah, Malaysia.

Kinnaird, M.F. 1997.Sulawesi Utara Sejarah Panduan Alam. GEF-Biodiversity Collection Project, Puslitbang Biologi-LIPI, Bogor.

Kottelat, M., A.J. Whitten, S.N. Kartikasari et al.,. 1993. Freshwater Fishes of Western Indonesia and Sulawesi. Periplus Edition. Indonesia.

Myers , G.S. 1938. Freshwater Fishes and West Indian Zoogeography. Smithsonian Rep., 1937: 339-364.

Myers, G.S. 1951. Usage of Anadromous, Catadormous and Allied Terms for Migratory Fishes. Copeia, 1949: 89-97.

Nelson, J.S. 1994. Fishes of the World, $3^{\text {rd }}$ editions. John Wiley \& Sons, Inc., New York.
Odum, E.P. 1971. The Fundamental Ecology (translation). Gadjah Mada University Press Yogyakarta.

Pielou, E.C. 1966. The measurement of Diversity Different Types of Biological Collections. Theoret. Biol., 13: 131-144.

Roberts, T.R. 1989. The freshwater fishes western Borneo. California Academy Science. San Fransisco.

Roberts, T.R. 1993. The Freshwaters Fishes of Java as Observed by Kuhl and van Hasselt i 1820-23. Zoologische Verhandelingen 28 (1993):1-94

Soeroto, B. and F. Tungka. 1996. The Inland Fishe and the Distribution of Adrianichthyoidea o Sulawesi Island, with Special Comments o the Endangered Species in Lake Poso. In D.J. Kitchener and A. Suyanto (eds) Proceedings of the International Conferenc on Eastern Indonesia-Australia Vertebrat Fauna, Manado, Indonesia, November 22 26, 1994: 1-5.

Southwood, T.R.E. 1971. Ecological Method: Chapman and Hall, London.

Weber, M. and L.F. de Beaufort. 1913. The Fishe of the Indo Australian Archipelag II,Malacopterygii, Myctophoidec Ostriophysi: I.Siluroidea. E.J. Brill Ltc Leiden.

Weber, M. and L.F. de Beaufort. 1916. The Fishe of the Indo Australian Archipelago III Ostriophysi: II. Cyprinoidea, Apodes Synbranchii. E.J. Brill Ltd, Leiden, xv+45. pp.

Weber, M. and L.F. de Beaufort. 1953. The Fishe of the Indo Australian Archipelag X,Gobioidea. E.J. Brill Ltd, Leiden.

Whitten, A.J., M. Mustafa and G.S. Henderson 1987. Ecology of Sulawesi. Gadjah Mad University Press. 
Komunitas Ikan Danau di Sulawesi Utara dan Gorontalo

Lampiran : Kelimpahan dan distribusi ikan pada danau-danau di wilayah Sulawesi Utara dan Gorontalo

\begin{tabular}{|c|c|c|c|c|c|c|c|c|c|}
\hline \multirow{2}{*}{ NO. } & \multirow{2}{*}{ SPESIES } & \multicolumn{6}{|c|}{ Lokasi/danau } & \multirow{2}{*}{$\begin{array}{c}\text { Kelimpahan } \\
(\Sigma . \text { Ind/st.) }\end{array}$} & \multirow{2}{*}{$\begin{array}{c}\text { Distributis } \\
(\% \text { FK })\end{array}$} \\
\hline & & Tondano & Limboto & Mooat & Tondok & $\sum$. ind & $\sum$. st & & \\
\hline 1. & Anguilla celebensis & - & 1 & - & - & 1 & 1 & 1 & 2.7 \\
\hline 2. & Barbodes gonionatus & - & 15 & - & - & 15 & 2 & 7.5 & 5.56 \\
\hline 3. & Cyprinus carpio & 2 & 2 & 17 & 4 & 25 & 4 & 6.25 & 11.11 \\
\hline 4. & Osteochilus hasselti & 2 & - & 64 & - & 66 & 2 & 33 & 5.56 \\
\hline 5. & Clarias batrachus & 10 & - & - & - & 10 & 1 & 10 & 2.78 \\
\hline 6. & Xiphophorus helleri & 4 & - & 142 & 5 & 151 & 3 & 50.33 & 8.33 \\
\hline 7. & Lutjanus argentimaculatus & - & 1 & - & - & 1 & 1 & 1 & 2.78 \\
\hline 8. & Oreochromis mossambicus & 4 & 9 & - & 1 & 14 & 3 & 4.67 & 8.33 \\
\hline 9. & O. niloticus & 103 & 7 & 24 & - & 134 & 3 & 44.67 & 8.33 \\
\hline 10. & Vallamugil sp. & - & 1 & - & - & 1 & 1 & 1 & 2.78 \\
\hline 11. & Ophieleotris aporos & 101 & 35 & - & - & 136 & 2 & 68 & 5.56 \\
\hline 12. & Anabas testudineus & 51 & 1 & - & - & 52 & 2 & 26 & 5.56 \\
\hline 13. & Trichogaster pectoralis & 10 & 1 & - & - & 11 & 2 & 5.5 & 5.56 \\
\hline 14. & T. trichopteras & 117 & 10 & 33 & 3 & 163 & 4 & 40.75 & 11.11 \\
\hline 15. & Channa striatus & 19 & 7 & 4 & - & 30 & 3 & 10 & 8.33 \\
\hline 16. & Poecillia reticulata & 3 & - & - & - & 3 & 1 & 3 & 2.78 \\
\hline 17. & Glossogobius aureus & - & 6 & - & - & 6 & 1 & 6 & 2.78 \\
\hline & $\sum$. Species & 12 & 13 & 6 & 4 & 819 & 36 & & \\
\hline
\end{tabular}

Keterangan:FK (frekuensi keterdapatan) 